1 Fundação Oswaldo Cruz (Fiocruz), Escola Politécnica de Saúde Joaquim Venâncio (EPSJV)

- Rio de Janeiro (RJ), Brasil. ariadna.alvarez@fiocruz.br

$\mathbf{2}$ Instituto Federal de Educação, Ciência e Tecnologia do Rio de Janeiro (IFRJ) - Rio de Janeiro (RJ), Brasil.

3 Universidade do Estado do Rio de Janeiro (Uerj), Instituto de Medicina Social (IMS) - Rio de Janeiro (RJ), Brasil.

\section{Por uma política da convivência: movimentos instituintes na Reforma Psiquiátrica Brasileira}

\author{
For a policy of conviviality: institutional movements in the Brazilian \\ Psychiatric Reform
}

Ariadna Patricia Estevez Alvarez $\mathbf{1}^{1}$ Neli Maria de Castro Almeida ${ }^{2}$, Angela Pereira Figueiredo ${ }^{\mathbf{3}}$

DOI: 10.1590/0103-1104202012725

RESUMO O propósito do artigo foi visibilizar o processo de constituição e implantação do Fórum Permanente de Centros de Convivência e Cultura (Ceco) no estado do Rio de Janeiro. Descreveram-se as etapas de sua gênese, os pressupostos teóricos de sua formulação e os desdobramentos legais, éticos e políticos dos dispositivos de convivência no âmbito da Reforma Psiquiátrica Brasileira. A experiência do Fórum forneceu três pistas metodológicas que podem ser úteis para a construção de políticas: 1) abertura, estar aberto à participação de todos, não restringir; 2) itinerância, movimentar-se sem se fixar em um mesmo lugar; 3) multiplicidade, desejar as diferenças e não obstruir o trânsito entre elas. Como produto desse movimento instituinte, foi gerado coletivamente o Projeto de Lei $\mathrm{n}^{\circ} 4.563 / 2018$, que cria a Política Estadual dos Centros de Convivência da Rede de Atenção Psicossocial no estado do Rio de Janeiro, apresentado pela frente parlamentar em defesa da saúde mental e luta antimanicomial na Assembleia Legislativa do Estado do Rio de Janeiro. O movimento em torno dos Ceco, dispositivos de promoção de encontros na cidade, sustenta-se a partir da produção do comum e busca dar sustentabilidade à política da convivência que resiste às tentativas de desmonte do SUS e ao neoliberalismo.

PALAVRAS-CHAVE Centros de convivência e lazer. Saúde mental. Políticas de saúde.

ABSTRACT This article intends to give visibility to the process of constitution and implementation of the Permanent Forum of Community and Cultural Centers (Ceco) in the state of Rio de Janeiro. Its inception, theoretical assumptions, and legal, ethical, and political developments among the Brazilian Psychiatric Reform have been described. The Forum's experience has provided three methodological clues, which are useful to design policies: 1) To be opened to everybody's participation, without restrictions; 2) to move without being stuck at the same place; 3) Multiplicity, the desire of the differences without obstructing the path along the way. As a product of this instituted movement, Law No. 4,563/2018 has been collectively generated to create the Community and Cultural Center's policy of the psychosocial network, in Rio de Janeiro, which has been presented by the parliamentary front in defense of mental health and the anti-asylum struggle at the Legislative Assembly of the State of Rio de Janeiro. The movement related to the Ceco, which are important devices to promote meetings in the city, is supported by the production of what is common and is aimed at the sustainability of conviviality in order to resist the dismantling of our public health system and neoliberalism.

KEYWORDS Centers of connivance and leisure. Mental health. Health policies. 


\section{Introdução}

O objetivo do artigo é dar visibilidade ao processo de constituição e implantação do Fórum Permanente de Centros de Convivência e Cultura (Ceco) no estado do Rio de Janeiro, buscando descrever as etapas de sua gênese, os pressupostos teóricos de sua formulação e, sobretudo, os desdobramentos legais, éticos e políticos dos dispositivos de convivência no âmbito da Reforma Psiquiátrica Brasileira (RPB).

Trata-se de um movimento instituinte de articulação entre usuárias, usuários, trabalhadoras, trabalhadores, familiares, estudantes, pesquisadoras, pesquisadores, gestoras, gestores vinculados ao campo da atenção psicossocial e da luta antimanicomial. Esse conjunto de sujeitos produtores de conhecimento em suas existências políticas tomou para si a responsabilidade de problematização e de enfrentamento das questões relacionadas com a política de convivência na saúde mental e com os temas daí decorrentes: inclusão social, direito ao trabalho, à educação, ao lazer, à cultura e à cidade.

Consiste em uma experiência coletiva de debate propositivo em torno das práticas relativas aos dispositivos de convivência, a qual reconhece os importantes avanços no campo da atenção psicossocial e, simultaneamente, interroga sobre a necessidade de novos dispositivos capazes de dialogar com a insurgência de novas demandas de inclusão da loucura nos territórios sociais, a partir da própria trajetória da RPB.

Entende-se aqui a RPB como um processo político e social complexo, composto de atores, instituições e forças de diferentes origens, e que incide em territórios diversos, nos governos federal, estadual e municipal, nas universidades, no mercado dos serviços de saúde, nos conselhos profissionais, nas associações de pessoas com transtornos mentais e de seus familiares, nos movimentos sociais e nos territórios do imaginário social e da opinião pública. Compreendida como um conjunto de transformações de práticas, saberes, valores culturais e sociais, é no cotidiano da vida das instituições, dos serviços e das relações interpessoais que o processo da reforma psiquiátrica avança, marcado por impasses, tensões, conflitos e desafios'.

Esse movimento, que deu origem ao Fórum, teve seu marco inicial no 'I Encontro de geração de trabalho e renda, cultura e saúde mental: políticas públicas, centros de convivência, inclusão social pelo trabalho e programas de arte e cultura', realizado em maio de 2018 na Universidade do Estado do Rio de Janeiro (Uerj). O Encontro, que contou com ampla participação popular, teve como foco a discussão em torno das práticas de geração de trabalho e renda por meio da construção conjunta de uma política de implementação dos Ceco como estratégia de promoção de saúde no estado do Rio de Janeiro.

$\mathrm{O}$ artigo se materializa, portanto, como produto do movimento iniciado em torno do dispositivo Ceco, a fim de relatar a experiência coletiva do Fórum. Constitui-se, também, em um recorte da pesquisa de doutorado da primeira autora, cujo desenvolvimento se deu concomitantemente à realização das reuniões do Fórum (iniciadas em maio de 2018, abrangendo oito edições até novembro de 2019).

Todas as autoras, para além de pesquisadoras, são, também, militantes do movimento instaurado ao redor do dispositivo. Acreditamos, nesse sentido, que a produção de conhecimento deve se dar de modo intrínseco ao movimento social, no diálogo constante com seus atores. A produção de conhecimento ocorre ao abordar a experiência da prática, na qual somos todos protagonistas, em busca da construção de políticas públicas que prezem tanto pela manutenção quanto pela ampliação dos dispositivos da rede de saúde, na defesa dos fazeres que sustentem a RPB e a saúde pública.

No que concerne às políticas públicas de saúde e o lugar que os Ceco têm ocupado ao longo da história da RPB, afirmamos que há um trânsito desse lugar entre a marginalidade, a inclusão e a exclusão das fronteiras do que é instituído e do que é instituinte. Segundo Baremblitt ${ }^{2}$, o instituinte aparece como um 
processo, enquanto o instituído emerge como um resultado. $\mathrm{O}$ instituinte transmite uma característica dinâmica, já o instituído transmite uma característica estabilizada. Como a vida é pura variação, há um permanente jogo entre formas instituídas e movimentos instituintes.

No que diz respeito à legislação que configura o dispositivo em questão, a Portaria ${ }^{\circ}$ 396 , de 7 de julho de 2005, que estabeleceu diretrizes para os Ceco, é mencionada pelo Ministério da Saúde no relatório 'Saúde Mental em Dados 11'3. No entanto, no mesmo ano de 2005, a portaria foi revogada, e não houve a criação de nova norma federal para seu funcionamento, financiamento ou implantação ${ }^{4}$, o que fragiliza a sustentação dos Ceco.

Com a Portaria $n^{\circ} 3.088$, de 23 de dezembro de $2011^{5}$, que instituiu a Rede de Atenção Psicossocial (Raps) no âmbito do Sistema Único de Saúde (SUS), os Ceco estão previstos na atenção básica. No inciso III dessa portaria, temos que o Centro de Convivência é unidade pública, articulada às Redes de Atenção à Saúde, em especial à Raps, em que são oferecidos à população geral espaços de sociabilidade, produção e intervenção na cultura e na cidade. O $\subseteq 4^{\circ}$ dessa portaria diz que os Centros de Convivência são estratégicos para a inclusão social das pessoas com transtornos mentais e pessoas que fazem uso de crack, álcool e outras drogas, por meio da construção de espaços de convívio e sustentação das diferenças na comunidade e em variados espaços da cidade. Já na Portaria ${ }^{0} 3.588$, de 21 de dezembro de $2017^{6}$, a da 'Raps do retrocesso', são propostas, resumidamente, a reintrodução do hospital dia, a instituição do Centro de Atenção Psicossocial Álcool e Drogas (Caps AD) tipo IV, que faz parte de uma estratégia para financiar comunidades terapêuticas, e a reinstalação de ambulatórios hierarquizados e desarticulados, indo na contramão de um cuidado pautado pelas práticas psicossociais. Os Ceco, assim como os consultórios na rua, ficam de fora do texto oficial da política de saúde mental do País.

Ferigato et al. ${ }^{7(92)}$ os definem como dispositivos multifacetados, ou como "[...] um movimento, um sistema tão flexível e aberto que dribla qualquer definição rígida de 'saúde', de 'cultura' ou de 'serviço". São dispositivos estratégicos, portanto, pois ativam experiências que extrapolam as fronteiras sanitárias, na promoção de práticas intersetoriais e na criação de encontros no território, por meio da produção de cuidado a partir da convivência.

A seguir, descreveremos em mais detalhes o processo de desenvolvimento das reuniões do Fórum, os caminhos das aprendizagens coletivas, a construção de um percurso teórico e os resultados obtidos ao longo dessa experiência.

\section{O Fórum}

Encontramos no conceito de comum, conforme proposto por Hardt et al. em 'Multidão'8 e "Bem-estar Comum"9(178), um ponto de ligação com Spinoza. Na 'Ética IV’’10, escólio da proposição 35 , Spinoza afirma que "da sociedade 'comum' dos homens, advêm muito mais vantagens do que desvantagens"9(178); e que

por meio da ajuda mútua, os homens conseguem muito mais facilmente aquilo de que precisam, e que 'apenas pela união das suas forças' podem evitar os perigos que os ameaçam por toda parte ${ }^{\mathbf{9}(178)}$.

Gostaríamos de pontuar que a 'união dessas forças' pode ser pensada como uma potência do 'comum'. Além de evitar os perigos que nos ameaçam, essa união de forças abre a possibilidade de imaginar e criar juntos outros mundos, outras maneiras de viver. Quanto aos perigos que nos ameaçam, em relação ao SUS, são muitos. No caso das políticas de saúde mental, a sensação é de que a cada dia os perigos se agravam. O SUS no Rio de Janeiro já ostentou o pior Índice de Desempenho do SUS (IDSUS) entre as capitais de todo o País"1.

Esses índices nos servem para elucidar as situações que atravessamos com os trabalhadores, nesse percurso entre o período 2016-2019, em que o SUS municipal do Rio de Janeiro 
sofreu ataques muito duros: equipes inteiras demitidas na atenção básica e atenção psicossocial, fechamento de clínicas da família, com destaque para o ano de 2019 em que a justiça precisou intervir na gestão municipal em defesa da população desassistida e dos trabalhadores sem pagamento ${ }^{12}$.

Em um contexto nacional, podemos constatar que, antes do golpe de 2016, os dados indicavam um significante caminho já percorrido na direção da desospitalização e da consolidação de uma atenção psicossocial essencialmente de base comunitária:

Considerando o investimento em serviços de atenção psicossocial, especialmente em Caps, que em '2014' ultrapassam a cifra dos 2 mil, e alcançam uma cobertura de 0,86 Caps por 100 mil/habitantes. Os gastos com hospitais caíram de 75,24\% em '2002' para 20,61\% em '2013', enquanto que, revertendo a política, os gastos com atenção psicossocial passam de '24,76\%'

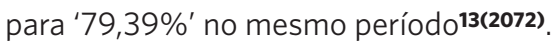

Até o ano de 2015, quando o Ministério da Saúde interrompeu a publicação regular de informações, observamos, por meio dos dados apresentados, que era crescente o investimento público em serviços do tipo Caps, o que fortaleceu o modelo psicossocial de cuidado proposto pela RPB, de substituição da rede hospitalocêntrica pelos serviços comunitários e territoriais.

De volta ao contexto do Rio de Janeiro, os manifestos dos movimentos sociais expõem os efeitos nefastos concretos no cotidiano. O informe do Núcleo Rio Sem Manicômios, intitulado 'A saúde mental adoece!'14, publicado em 2019, afirmava que os/as usuários/ as dos serviços de saúde mental que recebiam a Bolsa Rio (bolsa indenizatória para as pessoas que ficaram dois anos ininterruptos internadas ou mais antes da lei da Reforma Psiquiátrica) estavam há dois meses sem recebê-la; alguns Caps não tinham alimentação para os/as usuários/as diariamente, ou seja, eles/as estavam passando fome; os serviços residenciais terapêuticos estavam com os aluguéis atrasados, sendo os/as moradores/ as ameaçados/as de despejo, além dos/as cuidadores/as sem salário por três meses; houve Caps que teve a luz cortada em 2019 porque a prefeitura não pagou a conta; a prefeitura não investia em serviços de base comunitária, mas financiava hospitais psiquiátricos desenhando um aumento no número de leitos.

Em meio a esse cenário de desmonte do SUS, como preservar forças para construir? Como não perder nossa capacidade imaginativa, criativa, diante das terríveis notícias que nos atingem diariamente?

Sigamos pela pista do comum. O comum é aqui pensado como multiplicidade, como um composto de singularidades, em que essas singularidades estão elas próprias estabelecidas no comum. O comum baseia-se na comunicação entre singularidades que se manifesta por meio dos processos sociais colaborativos de produção. O comum não está dado, mas ele é produzido e tende a deslocar as dicotomias entre indivíduo e sociedade, subjetivo e objetivo, privado e público.

O comum é, ao mesmo tempo, pré-condição e resultado da produção da multidão. Ele é o que configura sua substância móvel e flexível. E multidão não se refere a uma 'identidade' única de um povo nem a uma 'uniformidade' das massas; mas são as 'diferenças em comunicação' que permitem o comum ser produzido e o agir em conjunto.

Sem desconsiderar as condições ambivalentes para o surgimento da multidão, que podem levar tanto à libertação como a um novo regime de exploração e controle, entendemos a multidão como um projeto de organização política, que só pode ser concretizado mediante as práticas sociais.

Fica a pergunta: como podemos constituir práticas sociais e movimentos em que 'as forças ativas tenham preponderância sobre as forças reativas'? Compartilhamos, então, a trajetória percorrida pelo Fórum dos Ceco, em um recorte de tempo (18 meses - maio de 2018 a novembro de 2019 - em 8 edições), entendendo 
que ele é, simultaneamente, produto e processo do movimento que debate a política da convivência.

Apostamos que as transformações acontecem por meio dos encontros, dos bons encontros, os que ampliam a capacidade de agir e pensar. Em 8 de maio de 2018, 50 anos depois do maio de 1968, durante o I Encontro, pela primeira vez, os Ceco do estado do Rio de Janeiro se encontraram e suas diferentes maneiras de trabalhar foram discutidas. Nessa ocasião, ocorreu também o lançamento do Guia Prático de Economia Solidária e Saúde Mental - 'Dá pra fazer!' -, produto que integra um conjunto de atividades apoiadas pelo Edital $\mathrm{CNPq} \mathrm{n}^{0} 89 / 2013$, referente à implantação da Incubadora Tecnológica de Cooperativas Populares do IFRJ e que foi construído, em 2017, por autoras que traziam diferentes experiências nos campos da saúde mental e da economia solidária. Éramos mais de 200 participantes ligados a cerca de 70 coletivos e/ou instituições diferentes. Uma pequena multidão composta de usuárias, usuários, trabalhadoras, trabalhadores, familiares, gestoras, estudantes, pesquisadoras, pesquisadores e militantes de variados campos, como saúde, arte, cultura e economia solidária.

Antecederam o I Encontro dois pré-encontros, um na Zona Centro-Sul e outro na Zona Norte-Oeste, com o objetivo de construirmos coletivamente como organizaríamos as diferentes pautas que estavam por ser debatidas. Ao fazermos os convites para compor as mesas do Encontro, percebemos uma prontidão enorme dos profissionais para falarem sobre seus trabalhos. Ficou explícito que o tema do trabalho que se faz nos Ceco sensibiliza muito. A mesa das experiências mais parecia uma roda, pois éramos dez pessoas em torno dela. Foram seis experiências Ceco apresentadas em cento e trinta minutos para um público extremamente atento a cada palavra. Todos escutaram o que cada um fazia, e cada um fazia diferente.

Na plenária final, reunimos e lemos publicamente todas as propostas dos grupos de trabalho. Depois de alguns destaques, aprovamos um conjunto de propostas para a confecção de um documento político: a 'Carta dos CECOs do Rio de Janeiro'. Encerramos este I Encontro com o embrião da carta nas mãos e a sensação de que foi um potente encontro. Contudo, aquele dia não havia sido suficiente. Havia muitos desafios a serem enfrentados juntos pela frente. Deliberamos, então, a criação do Fórum Permanente de Centros de Convivência do Estado do Rio de Janeiro. Desse I Encontro, foram gerados três produtos: a Carta, o Fórum e, posteriormente, o Projeto de Lei (PL) no 4.563/2018.

\section{Os Fóruns, a itinerância, a potência do comum: 0 método de raciocinar com pés}

No presente item, descreveremos os Fóruns que foram propostos durante o I Encontro e as suas principais discussões. Aqui, usaremos da narrativa em primeira pessoa do plural, pois todas somos parte do processo que se instaurou: de organizadoras do I Encontro, foi-nos possibilitada a criação de um coletivo militante que continuou se encontrando regularmente em prol dos avanços na RPB, tomando especificamente o dispositivo dos Ceco. Como já foi referido, consideramos que é nos encontros que podemos visar à transformação, assim como à produção de conhecimento que seja implicada a esses fazeres com o coletivo.

No I Fórum, também na Uerj, avaliamos o I Encontro e passamos para a Carta, que foi debatida em seus termos e composta por 11 propostas organizadas em 3 eixos: legislação e financiamento; infraestrutura; e formação. Foi sugerido que criássemos uma comissão dedicada à legislação, e prontamente seis pessoas se ofereceram para isso. Pactuamos que a carta seria impressa e que assinaturas de apoio seriam recolhidas. Combinamos que os fóruns seriam itinerantes de modo a ampliar a 
participação dos conviventes e comunidades locais. Essa também foi uma via para que todos pudessem conhecer o bairro, o acesso, os ares e os lugares de cada Ceco, usando o método de raciocinar com os pés ${ }^{15}$, aquele que caminha e vive o cotidiano.

O II Fórum aconteceu no Ceco da Zona Oeste, em Campo Grande, que tem a especificidade de funcionar dentro de uma lona cultural - na cidade do Rio de Janeiro, lona Cultural é o nome comum dado a uma série de teatros cobertos, administrados pela Secretaria Municipal de Cultura.

Os temas da pauta prevista eram: mobilidade urbana; comercialização de produtos da economia solidária; e estratégias de divulgação da carta. Contudo, para além da pauta prevista, havia uma pauta real que era saber como é a relação nos territórios com as lonas. O coletivo presente começou a pensar em estratégias de implementação de Ceco via outras lonas culturais, assim como se deu naquela exitosa parceria em Campo Grande. A ideia era que oficinas que aconteciam dentro do Caps pudessem ocorrer fora, nas lonas, e serem abertas a toda a comunidade. Nessa cena, vimos claramente como o Fórum possibilita um diálogo que amplia o poder de ação do coletivo de trabalhadores não só dos Cecos, mas também dos Caps. Além disso, foi sugerida a criação de um site como estratégia de comunicação da carta e divulgação do Fórum no mundo virtual.

No Museu de Arte Contemporânea, organizado pelo Ceco de Niterói, aconteceu o III Fórum. Cada uma das mais de 70 pessoas se apresentou dizendo seu nome e o que a tinha movido até ali, o que emocionou muitos conviventes. Instaurou-se um modo de fazer Fórum, dividido em dois momentos: um primeiro tempo focado no local, em que o Ceco anfitrião apresenta seu modo de fazer convivência e suas parcerias; e um segundo tempo focado no geral, em que se discutem os problemas comuns a todos e se pensam estratégias coletivas. A questão do que é atividade de convivência foi debatida intensamente, nos concentramos em criar respostas para a questão: o que deve ter no Centro de Convivência que não pode faltar de jeito nenhum? Conversas, pessoas que entendem a gente, união, fidelidade, harmonia, apoio, acolhimento melhor, coordenador, supervisor, psicólogo, apoio da prefeitura, van, ônibus, música, oportunidade de cursos e de trabalho, vale-social, registrar ações realizadas.

O tema do vale-social/passe livre retornou como algo imprescindível para a circulação na cidade. Essa é uma bandeira de luta não só dos Centros de Convivência, mas também ela se atualiza na essencialidade desse direito para a realização das práticas culturais, artísticas e de lazer no trânsito entre os espaços públicos. Surge então a palavra tratamento, pois, se é para o tratamento, esse direito de transitar no transporte sem pagar parece estar assegurado, ainda que com restrições.

Algumas falas defenderam o Centro de Convivência como tratamento. É isso que se quer? Afirmá-lo como tratamento? Quem trata, trata o quê? A quem o Centro de Convivência se dirige? Foi afirmada a necessidade de diálogo entre equipes Caps - Ceco. No fim, tivemos uma entre muitas definições possíveis do que é tratamento enunciada por quem usa o Ceco, que diz que tratamento é saúde, é se soltar para o mundo, é viver a vida cotidiana.

Os saberes formalizados, 'acadêmicos', são desmontados e remontados nos encontros com quem usa o dispositivo. Se afirmarmos que conviver também é manejar controvérsia, que estamos ali no Fórum convivendo, é preciso operar essa ética, em que múltiplas forças em tensão coemergem. Essa passagem nos remete a Schwartz \& Ruzza ${ }^{16}$ em que, ao correlacionarem a atividade militante - no caso, o 'saber sindical' e a elaboração de saberes -, baseiam-se na hipótese de que os saberes produzidos na confluência da experiência militante com a transmissão de conhecimentos são marcados por uma especificidade que possui uma tripla exigência: 1) exigência pedagógica, pois devem ser assimilados pelos militantes, pelo conjunto de trabalhadores; 2) exigência analítica, uma vez que a organização sindical tem a obrigação 
de compreender e interpretar o movimento da sociedade e do mundo do trabalho; 3) exigência prático-normativa, a fim de darem-se os meios para agir na e sobre esta sociedade e este mundo.

Em nossa análise, embora o Fórum não seja uma organização sindical, mas, sim, um movimento político, está sujeito a essa tripla exigência que os autores destacam. Há pesquisadores, professores, estudantes universitários no Fórum. As dimensões pedagógica e analítica interferem nas exigências prático-normativas, como, por exemplo, na elaboração de documentos políticos. A Carta dos Ceco já tem centenas de assinaturas, e propomos encaminhá-la para a frente parlamentar em defesa da saúde mental e luta antimanicomial da Assembleia Legislativa do Estado do Rio de Janeiro (Alerj). O fato de o movimento ganhar cada vez mais participantes produz alegria no coletivo, e aprendemos com Spinoza na 'Ética IV' Proposição 18 que “o desejo que surge da alegria é, em igualdade de circunstâncias, mais forte que o desejo que surge da tristeza"10(168). Sentimos que há ali uma predominância das forças ativas sobre as forças reativas.

Na sua IV edição, o Fórum se alocou no Ceco Trilhos do Engenho, no Engenho de Dentro. Contou com a participação de mais de 80 conviventes, alguns que passaram por internações psiquiátricas longas e outras mais curtas. Muitos falaram das mudanças positivas que perceberam em suas vidas a partir da participação no Ceco, entre os quais, uma pessoa disse que antes se considerava 'bicho do mato', que não conseguia ir ao portão, e hoje vai ao centro da cidade, e é apaixonada pela vida que tem.

No segundo tempo, o esboço do texto do PL formulado pela comissão de legislação foi apresentado e discutido. O tema da composição da equipe do Ceco trouxe muitas controvérsias a serem manejadas, múltiplas forças em tensão coemergiram. Profissional com ensino fundamental pode ser contratado? Precisa ter ensino médio completo? Artesanato requer ensino formalizado? Mencionar ou não no texto da lei as 14 profissões da área da saúde? Quais entram, quais ficam de fora?

Vivemos intensamente uma experiência democrática, uma democracia direta, sem representante, em que a voz de todos, seja lá quem fosse, era ali ouvida e considerada como de direito. $\mathrm{O}$ entendimento das autoras na análise sobre esse processo no que concerne à democracia se baseia em Spinoza no Tratado Político:

Esse direito, que é definido pelo poder da multidão, costuma-se chamar ESTADO, e está em plena posse desse direito, quem por consentimento comum, zela pelas coisas públicas, isto é, estabelece leis, interpreta-as, abole-as, fortifica as cidades, decide da guerra e da paz, etc. Se tudo isto se faz por uma assembléia saída da massa do povo, o Estado chama-se DEMOCRACIA 17(43).

A experiência democrática da construção do PL que cria a Política Estadual dos Centros de Convivência da Rede de Atenção Psicossocial no Estado do Rio de Janeiro - PL no 4.563/2018 18 - convoca-nos a elencar três diferentes sentidos das políticas públicas. O primeiro diz respeito às políticas relacionadas com um determinado governo, ou mandato: a política é pública, uma vez que atende à população, mas tem seu fim marcado quando se encerra uma dada gestão. $\mathrm{O}$ segundo sentido tem a ver com o Estado, nesse caso, a política pública é a política estatal que está para além do fim de um governo, ela tem mais institucionalidade do que as políticas de governo, sendo incorporada de tal forma que não pode ser facilmente extinta quando uma dada gestão termina. O terceiro sentido, que é aquele que exercitamos na experiência do Fórum, diz respeito às políticas públicas que se referem a uma gestão comum ${ }^{8}$.

O sentido de público se atrela à participação popular que constrói a política ativamente, e que, nesse caso, promove saúde por ser também uma atividade de convivência no contexto dos Ceco. Os Fóruns passaram a ser incorporados como uma atividade dentro da agenda cultural de alguns Ceco, indicando a inseparabilidade entre atenção e gestão. 
O Fórum seguinte, em sua quinta edição, foi organizado pelo Núcleo de Intervenções Culturais do Instituto Municipal Philippe Pinel, em Botafogo. Muitos projetos artístico-culturais da Zona Centro-Sul se fizeram presentes, o tema do carnaval foi marcante. Percebemos que ainda que não haja um Ceco implantado pela prefeitura naquela área, a Praia Vermelha tem uma vocação cultural fortíssima.

Há um projeto no papel sobre um Ceco na Zona Sul há muitos anos. Tivemos a notícia de que o PL n ${ }^{0} 4.563 / 2108^{18}$, protocolado na Alerj no fim de 2018, vai tramitar por cinco comissões antes de ir para votação. Pactuamos de acompanhar esse processo nos encontrando com essas comissões, quando necessário. Era véspera da audiência pública na Alerj que iria pautar o Estado como cofinanciador da Raps e estávamos mobilizados com ela. Fizemos uma faixa que clamava pela aprovação do PL $n^{0} 4.563 / 2018^{18}$; ela foi pendurada na Alerj durante a audiência.

OVIFórum foi realizado no Polo Experimental de Convivência, Educação e Cultura, em Jacarepaguá. O clima do mês da luta antimanicomial já ocupava o coletivo, o 18 de maio, dia da luta antimanicomial, estava por ser celebrado no Circo Voador, um espaço histórico de resistência da arte na cidade desde a década de 1980.

O corpo Fórum estava determinado em si mesmo e agiu na afirmação de uma política da convivência. Conversamos sobre fazer do Circo Voador, naquele sábado do 18 de maio, um grande Centro de Convivência, e assim foi. A organização e a realização do evento Circular da Loucura no Circo Voador foi uma alegre produção comum que concentrou a participação de movimentos diversos: luta antimanicomial, agroecologia, feminismo negro, cultura popular, população em situação de rua, economia solidária, entre outros. Nessa experiência, havia uma concordância entre os diferentes movimentos pela potência, pela afirmação da vida em liberdade, pela afirmação da convivência na cidade, enquanto política. Analisamos nessa experiência, à luz da filosofia de Spinoza, que as coisas estavam concordando em natureza, isto é, concordando em potência, e não em impotência ou em negação, conforme a 'Ética IV'10 Proposição 32.

O VII Fórum foi no Centro Cultural Professor Jair Nunes Macuco, que sedia o Ceco na cidade de Carmo, interior do estado, a 200 quilômetros da capital. Foram dois ônibus com mais de 40 pessoas e 2 vans de 15 pessoas que se moveram das cidades do Rio de Janeiro e de Niterói para conhecer a experiência de Carmo que fechou um manicômio e constituiu uma potente e articulada rede de saúde.

A experiência do Fórum em Carmo deixou notável que, no propósito do Fórum, para além de um debate da esfera macropolítica, está embutida a atividade de convivência. Passamos mais tempo viajando, ouvindo, tocando, cantando, fazendo música, poesia, teatro, feijoada do que nos dedicando à pauta. Foi feito um convite a um determinado modo de fazer política que compreende a atividade de convivência como um trabalho afetivo antimanicomial, aquele trabalho que nos provoca "construir conceitos e inventar práticas que operem em pleno campo produtivo de sociabilidade e de vida"19(124).

Contudo, as dimensões micro e macropolítica são inseparáveis. O Fórum também se ocupa com o fato de os Ceco não terem financiamento nem recursos próprios (não têm destinação orçamentária), de funcionarem sem o reconhecimento da gestão (não têm cadastro no SUS: Cadastro Nacional de Estabelecimentos de Saúde - CNES), de não haver parâmetros para a realização desse trabalho (não têm portaria nacional que regulamenta). Por isso, o VII Fórum também foi espaço para pautar a participação na XVI Conferência Nacional de Saúde, por meio de dois delegados eleitos, que levaram uma moção em prol dos Ceco que contou com mais de $90 \%$ de aprovação, e se articulou com outros estados da federação - e falar sobre o PL $\mathrm{n}^{\mathrm{0}} 4.563 / 2018^{18}$ já aprovado em quatro das cinco comissões da Alerj.

O último Fórum do ano de 2019, o VIII, aconteceu na Universidade Federal Fluminense (UFF), no auditório Marielle Franco, no Campus do Gragoatá. Esse Fórum ocorreu 
nove meses depois do primeiro do ano, e é interessante ver que entrou em ação o Coletivo Convivências da Universidade Federal do Rio de Janeiro (UFRJ) no Campus Praia Vermelha, que pretende pensar e trabalhar vivências que pensem a coletividade e o conviver, em diálogo com as atividades e estudos do dispositivo Ceco do SUS. Ele nasceu exatamente em uma área da cidade que não existia Ceco, mas com um projeto no papel há muito tempo para existir.

Em nossa análise, o surgimento desse coletivo é resultado do desenvolvimento da capacidade dialógica dos trabalhadores propiciada por diversos espaços; entre eles, o Fórum. Mais uma vez, confirmamos a hipótese da atividade de convivência como produção do comum. Portanto, a experiência com o Fórum nos fornece três valiosas pistas sobre a atividade da convivência, que também podem servir como elementos inspiradores na construção de políticas e movimentos: 1) Abertura, estar aberto à participação de todos, não restringir; 2) Itinerância, movimentar-se sem se fixar em um mesmo lugar; 3) Multiplicidade, desejar as diferenças e não obstruir o trânsito entre elas.

\section{A política da convivência em desafio ao neoliberalismo}

O percurso narrado serve para explicitar como a atividade de convivência é constituída pela construção desse plano comum. Um plano em que um corpo social se reapropria de sua potência criadora, de seu conatus, e é capaz de agir, de transformar a realidade. Chegamos, então, à formulação da tese de que a atividade de convivência é a produção do comum, desse plano que é, ao mesmo tempo, "aquilo que partilhamos e em que tomamos parte, pertencemos, nos engajamos"20(21).

Esse cenário está colocado em tempos de epidemia das drogas psiquiátricas ${ }^{21}$, de medicalização e patologização da vida, de ataques ao SUS e à democracia. Segundo Hardt et al. ${ }^{22}$, o neoliberalismo e sua crise instauraram algumas figuras da subjetividade, que destacamos em nossa análise: 1) o endividado, que é produzido pela hegemonia das finanças e sofre com o empobrecimento da vida que foi vendida ao capital; 2) o midiatizado, produzido pelo controle das informações e que sofre por sua atenção estar constantemente absorvida pelas telas; 3) o securitizado, produzido pelo regime de (in)segurança no estado de exceção, que sofre em ser vigia e vigiado, conduzido pelo medo; e 4) o representado, produzido pela corrupção da democracia.

Diante desses problemas, pensamos que urge nos encontrarmos presencialmente, urge fortalecer o comum. O Fórum foi se delineando como um mesmo espaço em que se fala sobre os efeitos da experiência Ceco na vida de cada convivente e se constrói política pública. Quando usamos a palavra con-viventes, estamos fazendo uma torção. Reconhecemos que embora haja diferenças entre os diversos lugares de enunciação (usuário, trabalhador do Ceco e de outros dispositivos, gestor, familiar, estudante, parceiro, pesquisador, militante, artista), ao propor que somos todos con-viventes, procuramos borrar essas fronteiras instituídas, de modo que todos possam se transformar na experimentação de outros lugares. Esse traço aponta para a potência da multiplicidade. Quanto mais pudermos entrar em contato com aquilo que é novo e é diferente, mais potentes nos tornaremos, conforme 'Ética IV'10, Proposição 38.

Parece que existe aí um fio da navalha. No processo constituinte por uma política da convivência, afirmamos a vida, a liberdade e a alegria, que se produzem nos encontros. Contudo, estamos cientes dos riscos da servidão em nome da liberdade. Não sabemos o que está por vir, o que pode resultar depois da aprovação do PL $\mathrm{n}^{0} 4.563^{18}$, por exemplo. O conteúdo desse projeto define Centro de Convivência como dispositivo intersetorial integrante da Raps, designa o que compete a ele, prevê a composição da equipe, e afirma que os Cecos não podem dispensar medicação ou 
prestar atendimento psiquiátrico ou psicoterápico. Confiamos na potência do comum para romper com as subjetividades assujeitadas: que possamos deixar de ser endividados e criemos outras interdependências produtivas; que possamos deixar de ser midiatizados e quebremos o feitiço das telas inventando outras formas de nos comunicar que fortaleçam os afetos políticos; que possamos deixar de ser securitizados e nos libertemos deixando de alimentar e ser alimentados pelo medo; que possamos, em vez de nos posicionarmos como representados, constituirmo-nos e falarmos com nossa própria voz no exercício das ações democráticas.

A defesa do coletivo, da criação de movimentos, dos Fóruns Permanentes, a partir do encontro, configura-se como resistência ante o modo neoliberal de organização de uma sociedade e perante ameaças cada vez mais graves que sofremos. Acreditamos na potência dos laços sociais, no incentivo ao protagonismo dos atores que configura os fazeres democráticos.

O movimento de resistência, assim, constrói-se por meio do social, da criação coletiva, do grupo, e se constitui nas relações de poder que se estabelecem em um contexto macropolítico. Por resistência, não a consideramos, assim como Barros ${ }^{23(57), ~ “[. . .] ~ c o m o ~}$ algo externo, que se põe contra o poder. Ela é ação na relação de poder". Acreditamos que os movimentos de criação do coletivo, nesse sentido, constituem-se em resistência, em produção de protagonismos, de subversões desejantes em meio aos mecanismos de poder dominantes e individualizantes que atualmente se configuram.

\section{Considerações finais: por retratos mutantes da Reforma Psiquiátrica Brasileira}

Os Ceco são dispositivos de promoção de encontros. O movimento que criamos em torno do dispositivo, nesse sentido, sustenta-se a partir do ideal da produção coletiva, da criação conjunta, na busca da sustentabilidade da política da convivência. Em um contexto neoliberal, no qual vivenciamos graves retrocessos no âmbito das políticas sociais, acreditamos que é necessário fortalecer os dispositivos de base comunitária, como os Ceco, incentivando as políticas de promoção de saúde do território.

Partimos do pressuposto da necessidade de um permanente processo de desinstitucionalização. Há uma polissemia do termo desinstitucionalização. Aqui nos interessa a perspectiva de desinstitucionalizar não como desospitalizar - uma redução de leitos psiquiátricos - ou como transinstitucionar - uma transferência de uma instituição para outra. Fazemos referência à desinstitucionalização da loucura como transformação das relações de poder entre instituições e sujeitos. Desinstitucionalização como um processo individual e coletivo de emancipação, de libertação, que conta com o componente do sofrimento individual, mas que não se reduz a ele. Ela envolve trabalhadores, administradores públicos, políticos, cidadãos comuns, na busca utópica, mas, paradoxalmente, realizável, de uma sociedade sem manicômios ${ }^{24}$.

Outro aspecto da política da convivência, no que corresponde à sua dimensão desinstitucionalizante, é a desconstrução do manicômio por meio de gestos elementares. Como diz Rotelli25, são gestos elementares: eliminar os meios de contenção; restabelecer a relação do indivíduo com o próprio corpo; reconstruir a capacidade de uso dos objetos pessoais; reconstruir o direito e a capacidade de palavra; eliminar a ergoterapia; abrir as portas; produzir relações, espaços e objetos de interlocução; liberar os sentimentos; restituir os direitos civis eliminando a coação, as tutelas jurídicas e o estatuto de periculosidade; reativar uma base de rendimentos para poder ter acesso aos intercâmbios sociais.

Compreendemos que o vigor desse movimento coletivo apenas foi possível em um contexto de avanço das conquistas da RPB, que permitiu a estabilização em território nacional, 
agora em risco, de uma rede comunitária de cuidados em saúde mental.

O percurso desse movimento instituinte pró-Centros de Convivência no campo público da atenção psicossocial aponta para a constituição de políticas intersetoriais que garantam o acesso a um amplo campo de direitos culturais, sociais e econômicos aos grupos vinculados aos serviços de saúde mental. São retratos mutantes em contínuos processos de transformação da RPB ensejados pelos sujeitos

\section{Referências}

1. Brasil. Ministério da Saúde. Reforma psiquiátrica e política de saúde mental no Brasil. In: Anais da Conferência Regional de Reforma dos Serviços de Saúde Mental: 15 anos depois de Caracas [internet]; 2005 Nov 7-10; Brasília, DF. Brasília, DF: Ministério da Saúde; 2005. [acesso em 2019 out 12]. Disponível em: http://bvsms.saude.gov.br/bvs/publicacoes/Relatorio15_anos_Caracas.pdf.

2. Baremblitt FG. Compêndio de análise institucional e outras correntes: teoria e prática. Rio de Janeiro: Rosa dos Tempos; 1992.

3. Brasil. Ministério da Saúde. Saúde Mental em Dados. [internet]. 2012. [acesso em $2020 \mathrm{fev} 29$ ]; 11. Disponível em: http://psiquiatriabh.com.br/wp/wp-content/uploads/2015/01/Dados-da-rede-assistencial-brasileira-2012-Ministerio-da-Saude.pdf.

4. Pacheco RF, Silva CR. (Com) Viver com a loucura: por um cuidado extramuros. Rev. Polis Psique [internet]. 2018 [acesso em 2020 fev 29]; 8(2):140-161. Disponível em: https://seer.ufrgs.br/PolisePsique/ article/view/78136/pdf. políticos que habitam esse lugar de tornar a vida possível para todos. Para todos.

\section{Colaboradoras}

Alvarez APE (0000-0003-1067-209X)*, Almeida NMC (0000-0002-9463-739X)*, Figueiredo AP (0000-0003-1464-3907)* contribuíram igualmente para a elaboração do manuscrito.
*Orcid (Open Researcher and Contributor ID).
5. Brasil. Ministério da Saúde. Portaria ${ }^{0} 3.088$, de 23 de dezembro de 2011. Institui a Rede de Atenção Psicossocial para pessoas com sofrimento ou transtorno mental e com necessidades decorrentes do uso de crack, álcool e outras drogas, no âmbito do Sistema Único de Saúde (SUS). Diário Oficial da União. 23 Dez 2011.

6. Brasil. Ministério da Saúde. Portaria $n^{\circ} 3.588$, de 21 de dezembro de 2017. Altera as Portarias de Consolidação $\mathrm{n}^{\circ} 3$ e $\mathrm{n}^{\circ}$ 6, de 28 de setembro de 2017, para dispor sobre a Rede de Atenção Psicossocial, e dá outras providências. Diário Oficial da União. 21 Dez 2017.

7. Ferigato SH, Carvalho SR, Teixeira RR. Os Centros de Convivência: dispositivos híbridos para a produção de redes que extrapolam as fronteiras sanitárias. Cad. Bras. Saúde Ment. [internet]. 2016 [acesso em 2020 fev 20]; 8(20):80-103. Disponível em: http:// pepsic.bvsalud.org/scielo.php?script=sci_arttext\&p id=S1984-21472016000300006.

8. Hardt M, Negri A. Multidão: Guerra e democracia na era do Império. Rio de Janeiro: Record; 2005. 
9. Hardt M, Negri A. Bem-estar comum. Rio de Janeiro: Record; 2016.

10. Spinoza B. Ética. 2. ed. Belo Horizonte: Autêntica; 2009.

11. Nalon T. Rio é capital com pior avaliação do atendimento do SUS, diz governo. [internet]. G1. 2012 Mar 01 [acesso em 2020 fev 29]. Disponível em: http:// g1.globo.com/ciencia-e-saude/noticia/2012/03/rio-e-capital-com-pior-avaliacao-do-atendimento-do-sus-diz-governo.html.

12. Regueira C. Mais de 22 mil prestadores de serviço para a saúde do Rio estão com os salários atrasados; Justiça manda bloquear R\$ 320 milhões. [internet]. G1. 2019 Nov 26. [acesso em 2020 fev 29]. Disponível em: https://gl.globo.com/rj/rio-de-janeiro/ noticia/2019/11/26/mais-de-22-mil-funcionarios-que-prestam-servico-para-a-saude-do-rio-estao-com-os-salarios-atrasados-justica-manda-bloquear-r-320-milhoes.ghtml.

13. Amarante P, Nunes MO. A reforma psiquiátrica no SUS e a luta por uma sociedade sem manicômios. Ciênc. saúde colet. [internet]. 2018 [acesso em 2020 fev 29]; 23(6):2067-2074. Disponível em: http://www.scielo.br/scielo.php?pid=S1413$-81232018000602067 \&$ script=sci_abstract $\&$ tlng=pt.

14. Núcleo Estadual do Movimento Nacional da Luta Antimanicomial do Rio de Janeiro. [internet]. [acesso em 2020 jan 16]. Disponível em: https://www.facebook.com/lutaantimanicomialrj/.

15. Venturini E. O caminho dos cantos: morar e intersetorialidade em saúde mental. Fractal: Rev. Psicol. [internet]. 2010 [acesso em 2020 jan 22]; 22(3):471-480 Disponível em: http://www.scielo.br/scielo.php?script=sci_abstract\&pid $=$ S1984$-02922010000900002 \& \operatorname{lng}=$ pt\&nrm=iso\&tlng=pt.

16. Di Ruzza R, Schwartz Y. De l'activité militante à elaboration de savoirs. Education Permanente [internet]. 2003 [acesso em 2020 fev 20]; 154(1):1-9. Disponível em: https://halshs.archives-ouvertes.fr/ halshs-00095787.
17. Spinoza B. Tratado Político. Rio de Janeiro: Nova Fronteira; 2013.

18. Rio de Janeiro. Assembleia Legislativa do Estado do Rio de Janeiro. Projeto de Lei ${ }^{\circ} 4.563$, de 20 de dezembro de 2018. Cria a política estadual dos centros de convivência da rede de atenção psicossocial no estado do Rio de Janeiro. 20 de dezembro de 2018 [internet]. [acesso em 2019 out 15]. Disponível em: http://alerjln1.alerj.rj.gov.br/scpro1519.nsf/18c1dd6 8f96be3e7832566ec0018d833/6fe33ee2aaf668a103 2583690053706 e? OpenDocument.

19. Lancetti A. Clínica Peripatética. São Paulo: Hucitec; 2008.

20. Kastrup V, Passos E. Cartografar é traçar um plano comum. In: Passos E, Kastrup V, Tedesco S, organizadores. Pistas do método da cartografia: a experiência da pesquisa e o plano do comum. Porto Alegre: Sulina; 2014. p. 15-42.

21. Whitaker R. Anatomia de uma epidemia: pílulas mágicas, drogas psiquiátricas e o aumento assombroso da doença mental. Rio de Janeiro: Fiocruz; 2017.

22. Negri A, Hardt M. Declaração - Isso não é um manifesto. São Paulo: N-1 edições; 2016.

23. Barros RB. Grupo: A afirmação de um simulacro. 3. ed. Porto Alegre: Sulina; 2009.

24. Venturini E. A linha curva: o espaço e o tempo da desinstitucionalização. Rio de Janeiro: Fiocruz; 2016.

25. Rotelli F, Leonardis O, Mauri D. Desinstitucionalização, uma outra via. In: Nicácio F, organizador. Desinstitucionalização. 2. ed. São Paulo: Hucitec; 2001. p. 17-59.

Recebido em 01/03/2020

Aprovado em 18/08/2020

Conflito de interesses: inexistente

Suporte financeiro: não houve 